\title{
Rehabilitation of anterior teeth with customised incisal guide table
}

\author{
Priyanka Mall, Kamleshwar Singh, Jitendra Rao, Lakshya Kumar
}

Department of Prosthodontics, Faculty of Dental Sciences, KG Medical University (Erstwhile CSMMU), Lucknow, Uttar Pradesh, India

\section{Correspondence to Dr Kamleshwar Singh, dr_kamleshwarsingh@yahoo. co.in}

\section{SUMMARY \\ Restoration of anterior guidance is a major challenge to the clinician in planning of all restorative treatments. An accurate anterior guidance is important for proper function, aesthetics, comfort and phonetics. This article describes anterior rehabilitation of a patient who met with a road traffic accident and lost his anterior teeth. Anterior guidance developed in the provisional restorations was accurately recorded in the customised incisal guide table and permanent restorations were fabricated accordingly.}

\section{BACKGROUND}

Restoring the missing anterior teeth arbitrarily can result in an interference with the envelope of motion, which can lead to premature contacts, cementation failures and tenderness of the abutment teeth. In restoring anterior teeth, incisal guidance was provided by the contacting surfaces of the maxillary and mandibular anterior teeth. ${ }^{1}$ It's steepness depends on horizontal and vertical overlap of the anterior teeth and lingual surfaces of the six upper anterior teeth. Incisal guidance is of prime importance in planning of all restorative treatments. Abnormal functional movements of the condyles can result from faulty incisal guidance, which can lead to temporomandibular joint dysfunctions. ${ }^{2}$ Eccentric functional occlusion, depends on right lateral, left lateral and protrusive guide factors in incisal guidance. The paths of movement of the condyle have little or no influence upon incisal guidance. An accurate incisal guidance is necessary for good aesthetics, phonetics, a minimal stress occlusion, functional efficiency and comfort of the patient. Restoration of multiple teeth that are missing or decayed, discoloured, developmental defects and worn out dentition are indications for occlusal rehabilitation. ${ }^{3}$ After determining appropriate anterior guidance it should be recorded and transferred accurately in permanent restorations. This paper describes recording of the anterior guidance, using provisional restorations which was borne by the patient for a reasonable period of time with satisfactory appearance, speech and comfort. Replication of these provisional restorations form in the definitive prosthesis was a crucial step in rehabilitation of this patient. The period of temporisation helped the patient in getting adjusted to the prosthesis during the transition period from his first visit to final restoration.

\section{CASE PRESENTATION}

A 26-year-old patient reported to the department of prosthodontics, who had lost his right upper central incisor, right and left lower central and lateral incisors in a road traffic accident around 1 year prior to admission. His prime concern was replacement of missing teeth owing to unaesthetic appearance. Left upper lateral incisor was fractured, leaving about $2 \mathrm{~mm}$ supragingival tooth structure. The incisal edges of maxillary left central incisor and right lateral incisor were also fractured (figure 1). The medical history of the patient was non-contributory. A review of the dental history of the patient revealed that the patient had sought dental care from an oral surgeon for immediate care following trauma. There was no derangement of the posterior occlusion due to trauma. The teeth that were to be used as abutments had no tenderness on percussion and the sulcus depth around them was normal.

\section{TREATMENT}

The treatment plan required a fixed partial denture replacing right upper central incisor using maxillary left central incisor and right lateral incisor as abutments. Post and core followed by complete coverage crown was planned for left upper lateral incisor. Mandibular incisors were replaced with fixed partial denture using left lower canine, right lower canine and first premolar as abutments. The right premolar was used in addition to right canine because the canine was periodontally compromised.

The following clinical steps were followed: All the interferences that prevent a full range of anterior guidance functional pathways were eliminated. Subsequently, diagnostic impressions were taken and casts were prepared and mounted on a semi adjustable articulator. A diagnostic wax-up was carried out on the maxillary and mandibular anterior teeth to establish an anterior guidance that provided for disclusion of posterior teeth in all eccentric excursions (figure 2). For recording the pretreatment condition, an additional set of models was prepared and mounted. Post and core was carried out on left upper lateral incisor and all the fixed partial denture abutments were prepared as per the treatment plan (figure 3). Putty indices

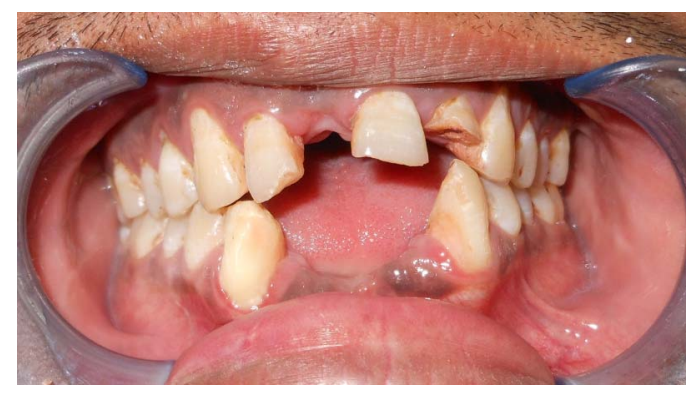

Figure 1 Preoperative view. 


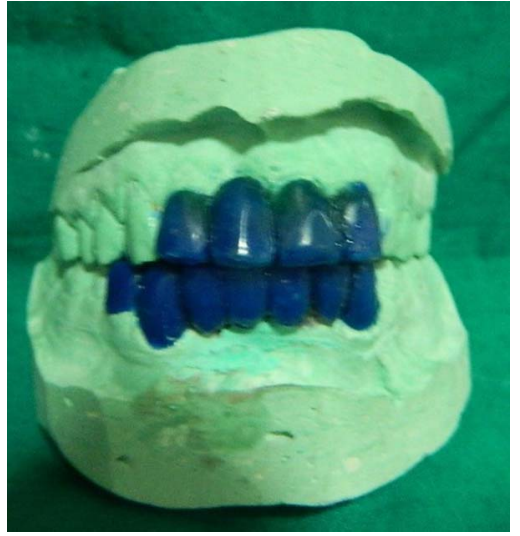

Figure 2 Diagnostic wax-up.

were prepared from the diagnostic wax-up and the tooth contours from the diagnostic wax-up were replicated into the provisional restorations (Protemp II, 3M ESPE). The provisional restorations were finished and polished cemented with a non-eugenol temporary cement for easy removal at subsequent appointments. The patient was left with these provisionals for a period of 2 weeks to evaluate aesthetics, phonetics and function with respect to anterior guidance.

A few days after restoration cementation the patient was recalled to verify the patient's comfort and satisfaction with the aesthetics. At the follow-up appointment, the accuracy of the occlusion was verified. It was checked whether the established functional pathways were in harmony with the envelope of function. Maxillary and mandibular impressions along with provisional restorations were taken and mounted after facebow transfer. A customised anterior guide with the help of autopolymerising acrylic resin was made to communicate precise details of anterior guidance to the technician (figure 4). A new mandibular cast with prepared abutments, was attached to the lower member of the articulator and final mandibular restorations were prepared. Now, the maxillary cast is replaced with a new cast with prepared maxillary abutments and maxillary final restorations were prepared. The final restorations were cemented (figure 5).

\section{OUTCOME AND FOLLOW-UP}

Follow-up appointments were carried out at regular intervals. The patient was satisfied with the aesthetics of prosthesis and was practicising good oral hygiene measures.

\section{DISCUSSION}

The lingual surfaces of the provisional restorations were contoured in such a way that they were in harmony with the functional envelope of motion. Successful restoration of lost anterior guidance was possible only if the satisfactory functional performance achieved with provisional restorations was present in

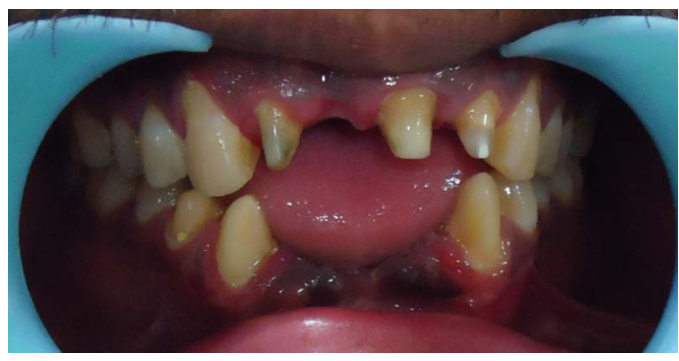

Figure 3 Photograph showing post and core.

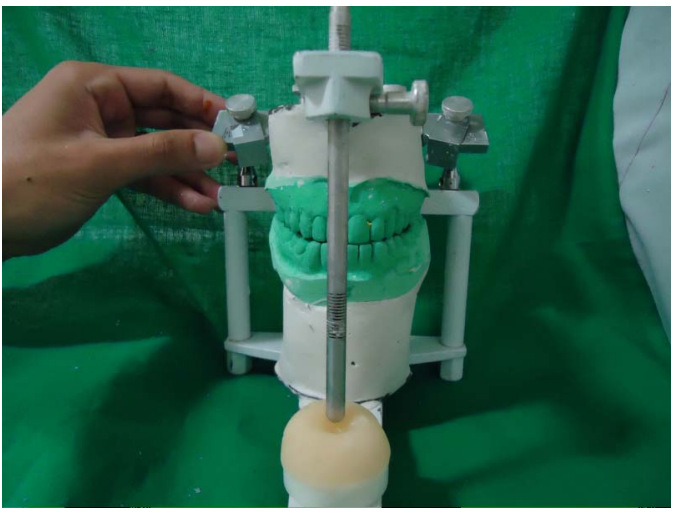

Figure 4 Customised incisal guidance.

final restorations also. Hence, communication of the details of anterior guidance with laboratory technician was very important. In this case, autopolymerising acrylic resin was used to make customised anterior guide table for duplication of functional guiding surfaces of anterior teeth. Sabek et al suggested an alternative procedure for reconstructing anterior guidance. To replicate the provisional restoration they used plaster templates, because they found them to be more accurate than silicone ones. According to them, the use of an articulator was not necessary. ${ }^{4}$ Alpert RL presented a precise method for recording and transferring anterior guidance called the anterior functional core. The anterior guidance developed in provisional restorations was accurately recorded in the customised incisal guide table and permanent restorations were fabricated accordingly. The provisional restoration provided an opportunity to evaluate phonetics, lip support, aesthetics, lip closure path, the envelope of function, the neutral zone, skeletal base relation, tooth position, abutment distribution, abutment bone support and tooth preparation. ${ }^{5}$ The patient was comfortable with the final restoration as, it was an exact replica of the provisionals with which the patient had already adjusted. ${ }^{7}$

\section{Learning points}

- The lingual surfaces of the provisional restorations were contoured in such a way that they were in harmony with the functional envelope of motion.

- Communication of the details of anterior guidance with laboratory technician was carried out by customising anterior guide table with the help of autopolymerising acrylic resin.

- The provisional restoration provided an opportunity to evaluate phonetics and aesthetics.

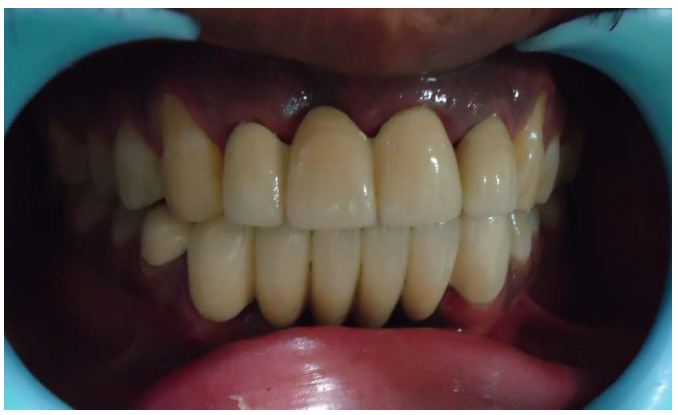

Figure 5 Postoperative view. 
Competing interests None.

Patient consent Obtained.

Provenance and peer review Not commissioned; externally peer reviewed.

\section{REFERENCES}

1 Schuyler $\mathrm{H}$. The function and importance of incisal guidance in oral rehabilitation. J Prosthet Dent 2001;86:219-32.

2 Schuyler $\mathrm{CH}$. Factors of occlusion applicable to restorative dentistry. J Prosthet Dent 1953:3:781.
3 Rosenstiel SF, Land MF, Fujimoto J. Contemporary fixed prosthodontics. 3rd edn. Mosby, 2001:202-13.

4 Sabek M, TrBvelo A. Alternative procedure for reconstructing anterior guidance using an autopolymerizing resin pattern. J Prosthet Dent 1996;76:550-3.

5 Alpert RL. A method to record optimum anterior guidance for restorative dental treatment. J Prosthet Dent 1996;76:546-9.

6 Dawson PE. Determining the determinants of occlusion. Int J Periodont Rest Dent 1983;6:8-21.

7 Rieder CE. The use of provisional restorations to develop and achieve esthetic expectation. Int J Perio Rest Dent 1989;9:136-7.

Copyright 2013 BMJ Publishing Group. All rights reserved. For permission to reuse any of this content visit http://group.bmj.com/group/rights-licensing/permissions.

BMJ Case Report Fellows may re-use this article for personal use and teaching without any further permission.

Become a Fellow of BMJ Case Reports today and you can:

- Submit as many cases as you like

- Enjoy fast sympathetic peer review and rapid publication of accepted articles

- Access all the published articles

- Re-use any of the published material for personal use and teaching without further permission

For information on Institutional Fellowships contact consortiasales@bmjgroup.com

Visit casereports.bmj.com for more articles like this and to become a Fellow 